Religare, ISSN: 19826605, v.16, n.2, dezembro de 2019, p.576-592.

\title{
O ensino religioso nas escolas públicas do Estado do Amapá: orientações curriculares e expectativas de aprendizagem
}

\author{
Religious education in the public schools of the state of \\ Amapá: curricular guidelines and learning expectations
}

\author{
Jane Cristina Oliveira ${ }^{1}$ \\ Joselina Souza de Oliveira ${ }^{2}$ \\ Vânia Célia Ventura de Sousa ${ }^{3}$ \\ Maria Raimunda Valente de Oliveira Damasceno ${ }^{4}$
}

\section{Resumo}

O presente artigo tem como objetivo abordar o ER nas escolas públicas do Estado do Amapá. Trata-se do resultado de um estudo descritivo de natureza qualitativa que adotou a pesquisa bibliográfica e a análise documental como forma de investigação. Os resultados pontuaram aspectos relacionados às orientações curriculares dispensadas pela Secretaria Estadual de Educação (SEED) e pelo Conselho Estadual de Educação (CEE), além de outras orientações. Foram elencadas as expectativas de aprendizagens para o componente ER no Ensino Fundamental das escolas públicas que compõem a rede estadual de ensino do Amapá. Concluiu-se que o ER tem sido uma tarefa desafiadora, que não pode se influenciar por apenas uma concepção religiosa, mas deve adotar em suas práticas educativas a laicidade e as reformulações promovidas pelas legislações educacionais em nível nacional e estadual, as quais, em sua totalidade garantem uma educação para todos, igualitária e provedora de acesso ao processo ensino e aprendizagem, sem utilizar métodos ou conteúdos seletivos e nem modelos para se afirmar o trabalho do fenômeno religioso na escola.

Palavras-chave: Ensino Religioso; Currículo; Aprendizagem; Amapá.

\footnotetext{
${ }^{1}$ Mestranda em Ciências das Religiões pela Faculdade Unida de Vitória. Especialista em Metodologia do Ensino de Meio Ambiente e Novas linguagens e novas abordagens da Língua Portuguesa. Licenciada Plena em Letras-habilitação Português. Email: janemestrado2019@gmail.com

2 Mestranda em Ciências das Religiões pela Faculdade Unida de Vitória. Especialista em Metodologia do Ensino de Meio Ambiente e em Novas linguagens e novas abordagens da Língua Portuguesa. Licenciada Plena em Letras-habilitação Português. E-mail: josyap40@yahoo.com.br

3 Mestranda em Ciências da Religião pela Faculdade Unida de Vitória. Especialista em Psicopedagogia e em Gestão Educacional. Graduada em Letras e em Pedagogia. E-mail: vania_cvs@hotmail.com

${ }^{4}$ Mestranda em Ciências das Religiões pela Faculdade Unida de Vitória. Doutora em Ciências da Educação. Mestra em Antropologia. Bacharel em Sociologia e Serviço Social. E-mail: maria_damasceno@hotmail.com
} 
Religare, ISSN: 19826605, v.16, n.2, dezembro de 2019, p.576-592.

\section{Abstract}

This article aims to address the RE in public schools in the state of Amapá. This is the result of a qualitative descriptive study that adopted bibliographic research and document analysis as a form of investigation. The results punctuated aspects related to the curriculum guidelines provided by the State Secretariat of Education (SEED) and the State Board of Education (CEE), in addition to other guidelines. The learning expectations for the ER component in the elementary school of the public schools that compose the state school of Amapa were listed. It was concluded that the RE has been a challenging task, which cannot be influenced by just a religious conception, but must adopt in its educational practices the secularity and the reformulations promoted by the national and state educational legislations, which, in their The totality guarantees an education for all, egalitarian and provider of access to the teaching and learning process, without using selective methods or contents or models to assert the work of the religious phenomenon in the school.

Keywords: Religious Education; Curriculum; Learning; Amapá.

\section{Introdução}

A proposta temática escolhida para a construção desse estudo tem como foco a abordagem do Ensino Religioso (ER) nas escolas públicas do Estado do Amapá, enfatizando aspectos relacionados às orientações curriculares e expectativas de aprendizagens. Apresenta-se dessa forma revisão de literatura que prioriza considerar a escola como um reflexo da sociedade em que se encontra e funciona, tanto por meio dos que nela ingressam, como por aqueles que ali trabalham, uma vez que também são oriundos deste mesmo contexto social, possuindo a mesma gama de crenças e atitudes, tal qual, qualquer grupo de pessoas.

Nesse preâmbulo de diversidades humanas identifica-se a reprodução dos valores, crenças e as prioridades que o educador pode utilizar em sala de aula para trabalhar com os alunos. Nessa perspectiva, trabalhar o componente ER, planejando-o para ser aplicado em realidades distintas, até certo ponto, é tarefa desafiadora aos educadores(as), requerendo-se identificar as dissonâncias com o preconizam os documentos oficiais e legislações educacionais para que acrescido 
Religare, ISSN: 19826605, v.16, n.2, dezembro de 2019, p.576-592.

ao processo de formação, possa-se estudar e interpretar o fenômeno religioso com base no convívio social/escolar, na construção de práticas educativas enunciadoras da identificação de problemas e também de soluções para a mudança de concepções e de atitudes frente aos paradigmas presentes na sociedade.

Na última década, as legislações brasileiras e os documentos oficiais tem proferido o componente ER como uma proposta de convergir entendimentos sobre a diversidade social e cultural da sociedade. Mas há desafios que ainda precisam ser superados para que tal convergência frutifique, especialmente no que tange as influências das diversas crenças religiosas que são contra os ideais de tolerância religiosa propostos pelo Estado laico (CURY, 2018; PINTO, 2017; DORVILLÉ E SELLES, 2018); as questões de gênero e sexualidade, entrecruzando esse debate à relação laicização e religião (OLIVEIRA; MIRANDA; SILVA, 2018); o ensino confessional e a dimensão religiosa da educação, da concepção de liberdade religiosa e da formação educacional cidadã (ROCHA, 2018); e, como o ER pode contribuir para que os alunos possam manifestar suas convicções religiosas de forma madura sem ferir o posicionamento e a liberdade do outro.

A superação dos desafios comentados anteriormente têm promovido mudanças curriculares nos projetos das unidades da federação. No âmbito do Estado do Amapá, identificaram-se orientações para que os professores lecionam o componente ER como área do "conhecimento humano com vista a subsidiar o aluno na compreensão do fenômeno religioso e do sagrado, presentes nas diversas culturas e sistematizados por todas as tradições religiosas [...]" (AMAPÁ, 2006, p. 108).

Mas, há outras orientações que foram elencadas no bojo do estudo para elucidar o objetivo geral da pesquisa, abordar o ER nas escolas públicas do Estado do Amapá, e, especificamente, pontuar aspectos relacionados às orientações curriculares dispensadas pela Secretaria Estadual de Educação (SEED) e pelo Conselho Estadual de Educação (CEE), além de outras orientações; bem como, 
Religare, ISSN: 19826605, v.16, n.2, dezembro de 2019, p.576-592.

elencar as expectativas de aprendizagens para o componente ER no Ensino Fundamental das escolas públicas que compõem a rede estadual de ensino do Amapá.

A pesquisa foi classificada quanto ao seu procedimento como bibliográfica e documental. Nessa perspectiva, o levantamento das várias fontes de pesquisa coadunaram para além de resolução de problemas e identificação de hipóteses, também confluíram para direcionar outras fontes de coleta visando recolher informações preliminares sobre o campo de interesse, o componente ER nas escolas públicas do Amapá (LAKATOS; MARCONI, 2010).

Esse artigo foi desenvolvido em duas seções que se interligam reflexivamente e criticamente. Na primeira parte foram apresentados ao leitor questões importantes sobre a organização e orientações curriculares dispensadas pelos órgãos competentes em dirimir, em âmbito nacional e estadual sobre políticas públicas educacionais e, assim, interferindo no Ensino Religioso. E na última seção foi feita abordagem mais crítica acerca do ER no Ensino Fundamental frente às políticas públicas as quais a eles se destinam.

\section{Orientações curriculares para o componente ER no Estado do Amapá}

Marcos Reis e Katia Anjos (2017) ao explorarem sobre perfil da disciplina ER, ministrada nos anos iniciais do Ensino Fundamental da educação pública do estado do Amapá, conseguiram organizar informações sobre as tendências atuais para a organização do currículo desse componente. Entre vários aspectos, abordaram-no como prática educativa pautada na diversidade religiosa requerendo dos envolvidos "diálogo, discussão e formação" para garantir o que preconiza a Lei n. 9.394/1996 (BRASIL, 1996) e o Parecer CES/CNE sob n. 09/2001 (BRASIL, 2001), e assim, efetivar a nova proposta pluralista de ER. Mesmo assim, diversos conflitos proselitistas têm promovido barreiras (intolerância religiosa só 
Religare, ISSN: 19826605, v.16, n.2, dezembro de 2019, p.576-592.

para citar um exemplo) para aplicar no currículo essa nova abordagem metodológica de ensino elaborada.

Em relação aos conflitos proselitistas mencionados anteriormente, nos estudos de Gustavo Branco (2018) confirmou-se que há realidades escolares em que a vedação ao proselitismo contida no artigo 33 da LDB tem sido interpretada erroneamente, quando deve se levar em consideração o aspecto ético para se evitar que a sala de aula de ER nas escolas públicas se torne a expressão de uma única tradição religiosa.

Questão que também foi abordada por Maria Cavalcante (2019) ao expor que o proselitismo ainda é fruto do despreparo humano para conviver com a diversidade, demonstrando-se acontecer de forma precária educar e lidar com diferentes identidades e perspectivas culturais presentes na sociedade e que envolvem aspectos religiosos. Os educadores devem evitar conflitos proselitistas e entenderem que ER devem dotar os alunos de conhecimentos da história das religiões e fomentar a aceitação de que existem realidades diferentes das suas e que precisam ser respeitadas.

No Amapá, não há exceções de regras, há na verdade um vínculo histórico entre setores educacionais com as igrejas cristãs, que mostram um processo de influências socioculturais que têm permeado a atuação autônoma da SEED contrário ao que preconizam as leis educacionais, pois é uma relação que tem favorecido entidades de viés cristão e tem excluído representações plurais de religiões não cristãs, o que afeta diretamente a formulação do ER, evidenciando, no caso em apreço, a possível marginalização das religiões de matrizes africanas no processo educativo.

Importa considerar que as pesquisas bibliográficas realizadas mostraramse pouco eficazes na demonstração dos resultados do ER como componente e como política pública estadual de ensino. Os resultados mostraram a existência de apenas três publicações que abordam essa perspectiva teórica, sendo: o estudo de Maria de Lourdes Vulcão (2016) que aborda os processos atuais de construção 
Religare, ISSN: 19826605, v.16, n.2, dezembro de 2019, p.576-592.

da disciplina ER na Educação básica por meio da interação e atuação dos professores que compõem a Associação de Professores de Ensino Religioso do Amapá (APERAP); as pesquisas de Tatiane Monteiro (2012) que recomendou o uso das Mídias no ER como instrumento de leitura da realidade, conjugado ao entendimento das relações existentes entre os elementos desse espaço, contribuindo para a plena cidadania; e, sendo o mais utilizado nesse artigo, a pesquisas de Marcos Reis e Katia Anjos (2017) por refletir sobre o fazer pedagógico do ER no contexto atual, buscando repensá-la e destaca-la de um modelo confessional e proselitista cristão para uma representação pluralista.

A pesquisa realizada por Marcos Reis e Katia Anjos (2017), ao comparar os discursos de professores do 5..$^{\circ}$ ano do Ensino Fundamental de escolas públicas com os de assessores pedagógicos da SEED, identificaram o distanciamento de valores e a exclusão de determinados conteúdos, como evidenciado nos excertos extraídos desse estudo.

Eu procuro trabalhar o negócio de princípios que têm tudo a ver com todas, né...? Bondade humildade união companheirismo, trabalhos em grupo, um ajudando o outro. Do amor, eu falo do amor, e aqui e acolá eu falo dos personagens bíblicos, pois também, a bíblia é universal né? Olha segunda-feira... Segunda ou terça eu vou trabalhar sobre a história de Salomão. O que que Salomão foi? Foi um homem que Deus escolheu para ser rei! [...]. É princípios (PROFESSORA apud REIS e ANJOS, 2017, p. 23).

Mais nessa questão, nossa orientação de escola é que não deveria existir nada relacionado à religião. Então a nossa orientação é essa: trabalhar mais a questão do respeito, solidariedade, amizade, mais a questão mesmo de valores e não da religião em si (ASSESSORA PEDAGÓGICA apud REIS e ANJOS, 2017, p. 23).

Apesar da proximidade de opiniões entre professores e assessores pedagógicos identificados na pesquisa de Marcos Reis e Katia Anjos (2017), podese identificar nos discursos a forte influência de apenas um determinado ponto de vista religioso sobre a construção dos conteúdos ministrados em sala de aula, a visão cristã, que em seus ensinos, centraliza-se na imagem central de Jesus como 
Religare, ISSN: 19826605, v.16, n.2, dezembro de 2019, p.576-592.

amigo de todos ou então em personagens da bíblia, que, ao serem utilizados como conteúdos curriculares se contradizem com a orientação de interferência mínima possível de questões religiosas no ER e nos conteúdos ministrados em sala de aula.

Abordagem similar foi realizada por Jair Silva e Lázara Coelho (2018) ao se proporem abordar sobre o ER sob a perspectiva cristã, postularam que o currículo é limitado e tende a não considerar a diversidade e o multiculturalismo em suas posições ideológicas, limitando-se a abordar aspectos das bases filosóficas da educação cristã e descontextualizando-a das práticas educacionais não cristãs.

E nos estudos de Adriana Figueirêdo (2017), no caso de práticas proselitistas nas escolas públicas nas aulas de ER, recomenda a ampliação dos debates acerca do ER laico e que insira a diversidade religiosa (indígena e afrobrasileira, por exemplo) presente no cotidiano escolar, através de ações e práticas pedagógicas possíveis de incluírem concepções excluídas e silenciadas pela tradição cristã, e assim, construir uma perspectiva dialogal.

Consta no documento “Diretrizes Curriculares da Educação Básica do Estado" (AMAPÁ, 2016) a proposta curricular para o Ensino Religioso, a qual elenca que o ensino deve se pautar em conteúdos que orientam as características descritas na tabela 1.

Tabela 1 - Conteúdos para o ensino de ER na Escola Pública do Amapá.

\begin{tabular}{|l|l|l|}
\hline \multicolumn{3}{|c|}{ Conteúdos a serem trabalhados Conteúdos a serem trabalhados } \\
\hline$\checkmark$ Respeitar a diversidade cultural e & $\checkmark \quad$ Identificar diferentes tradições religiosas, \\
tradições religiosas dos povos; & ressaltando a importância da religião na vida \\
$\checkmark$ Conhecer os textos sagrados, percebendo- & das pessoas, vivenciando o diálogo e as \\
os como referenciais de ensinamentos sobre a & diferenças religiosas; \\
fé e a prática das tradições religiosas; & $\checkmark \quad$ Reconhecer estruturas simbólicas, \\
$\checkmark \quad$ Conhecer alguns espaços sagrados & gráficas, oralidade e imaginação; \\
existentes na comunidade; & $\checkmark \quad$ Simbologia religiosa e seus significados \\
$\checkmark \quad$ Identificar divindades próximas: Deus, & para a prática das tradições religiosas. \\
deuses, personificações heroicas; & \\
\hline
\end{tabular}

Fonte: AMAPÁ (2016). 
Religare, ISSN: 19826605, v.16, n.2, dezembro de 2019, p.576-592.

A proposta curricular para o Ensino Religioso ainda elenca que para as etapas do Ensino Fundamental espera-se que a ministração dos conteúdos possa ocorrer sempre considerando o respeito à diversidade cultural e religiosa dos educandos, promovendo-se nas aulas, a motivação para alunos possam dialogar entre si sobre os conteúdos e consigam compreender adequadamente o sentido de cada conteúdo e, possam ou não, optar em aplica-los em sua realidade familiar e social, sem a interferência de um único enfoque religioso, mas pela visão multicultural. Como proposto nesses documentos:

[...] as aulas devem ser dinâmicas, tendo o objetivo de socialização ao tema em estudo. Envolver os alunos na prática, com novas sugestões e ideias (jogos, brincadeiras, gincanas). Mostrar aos educandos a importância da Disciplina Ensino Religioso através da valorização de suas experiências, como também das suas respectivas religiões, não interferindo nas mesmas (através de produção de textos e relatos). Para alcançar esses objetivos é essencial que as aulas sejam desenvolvidas num clima de diálogo, de abertura para debate, em que todos tenham a oportunidade de se posicionar, participando de forma ativa, num ambiente agradável, descontraído e acolhedor. É fundamental que o professor viva com a classe a experiência da inter-relação de fé e de vida (AMAPÁ, 2016, p. 5).

Os problemas e desvios de finalidade no ER na escola pública do Amapá não são questões curriculares, mas requerem a mudanças de paradigmas presentes no processo de formação e a prática dos(as) professores(as) desse componente. Para esses profissionais a maneira fenomenológica, de pôr entre "parênteses" as suas verdades, certezas e seguranças religiosas em respeito a uma escola pública laica e culturalmente marcada pela diversidade religiosa ainda tem sido vista como desafio e assim, promovem esse silencio que impede que o ER enfoque a diversidade social, cultural e religiosa.

Na pesquisa realizada por Marcos Reis e Katia Anjos (2017) identificou-se algumas opiniões de professores sobre a necessidade de habilitação/ formação inicial e continuada para lecionar com o componente ER. Em um dos discursos apresentados pelos autores, a professora reconheceu que a formação se faz 
Religare, ISSN: 19826605, v.16, n.2, dezembro de 2019, p.576-592.

necessária não só na questão da pluralidade religiosa, mas nas questões de gênero e diversidade:

\begin{abstract}
A gente tem se preparar pra isso, a gente tem que respeitar. Igual em relação a sexo, assim a homossexualismo (sic), porque infelizmente... Há tipos de família. Porque quando a gente fala de família, é a nossa família, mas só que hoje em dia já tem vários tipos de família. Eu por exemplo trabalhei família semana passada, mas o nosso tipo de família! Porque na minha sala ainda não tem, eu penso que não, mas vai ter. Vai chegar esse momento e vai ser natural. Então a gente tem que se preparar, porque uma hora ou outra a gente vai se deparar com essas situações (PROFESSORA apud REIS e ANJOS, 2017, p. 24).
\end{abstract}

Os discursos que foram colhidos da pesquisa de Marcos Reis e Katia Anjos (2017) não foram escolhidos aleatoriamente, tiveram um proposito, pois demonstraram a distancia com que os professores(as) de ER sentem em lidar com assuntos da atualidade que envolvem a sociedade e a realidade cultural e porque não incluir nesse aspectos, as asperezas religiosas que possam dificultar ainda mais um ensino que não identifique o valor da formação cidadã nas práticas e atitudes que favoreçam os princípios de: amizade, cooperação, respeito, partilha, atitudes solidárias, sem, necessariamente, relacioná-los a um determinado e específico pensamento religioso, no caso o cristão.

Por isso, os(as) professores(as) devem levar em consideração que o componente ER nas escolas públicas do Amapá deve ser planejado em conformidade com o que preconiza a estrutura curricular proposta e descrita nas “Diretrizes Curriculares da Educação Básica do Estado” (AMAPÁ, 2016) que organizou os conteúdos em eixos, conforme a tabela 2.

Tabela 2 - Estrutura curricular proposta pela SEED para ER.

\begin{tabular}{|lll|}
\hline \multicolumn{1}{|c|}{ Ano } & & \multicolumn{1}{c|}{ Eixos estruturantes de ER } \\
\hline $\mathbf{1}^{\mathbf{0}}$ ao $3^{\mathbf{o}}$ Ano & $\bullet$ & Eu - ser social e histórico. \\
& $\bullet$ & Ethos. \\
& $\bullet$ & Culturas e Tradições religiosas. \\
\hline $4^{\mathbf{0}}$ ano & $\bullet$ & Cuidado com a vida. \\
& $\bullet$ & História cultural dos rituais, cotidiano e sagrado. \\
\hline
\end{tabular}


Religare, ISSN: 19826605, v.16, n.2, dezembro de 2019, p.576-592.

\begin{tabular}{|c|c|}
\hline & $\begin{array}{l}\text { - Espaço sagrados e comemorativos de fé. } \\
\text { - Textos sagrados orais e escritos. }\end{array}$ \\
\hline 5. ${ }^{\circ}$ ano & $\begin{array}{l}\text { - Fenômenos religiosos, espiritualidade religiosa para a vida e a morte. } \\
\text { - As regras e os valores morais das tradições religiosas para a convivência } \\
\text { - } \text { Histórias, estruturas, revelações nas diferentes tradições religiosas. } \\
\text { - Relações religiosas. }\end{array}$ \\
\hline $6^{\circ}$ ano & $\begin{array}{ll}\text { - } & \text { Identidade e Fundamentos do Ensino Religioso. } \\
\text { - } & \text { Culturas e Tradições Religiosas. } \\
\text { - } & \text { Tradição Religiosa e Fenômeno Religioso. } \\
\text { - } & \text { História das Religiões I. }\end{array}$ \\
\hline $7^{\circ}$ ano & $\begin{array}{l}\text { - } \quad \text { Símbolos e Identidades Religiosas. } \\
\text { - } \quad \text { Vivência com o mistério do Transcendente. } \\
\text { - História das Religiões II. } \\
\text { - A presença do Transcendente no texto e na Arte. }\end{array}$ \\
\hline $8^{\circ}$ ano & $\begin{array}{l}\text { - A presença do Transcendente no Mundo. } \\
\text { - Fenômeno Religioso no contexto Social. } \\
\text { - } \quad \text { Rituais e Símbolos Sagrados. }\end{array}$ \\
\hline $9^{\circ}$ ano & $\begin{array}{l}\text { - } \quad \text { Liderança uma questão de compromisso. } \\
\text { - } \quad \text { Os fundamentos teóricos do Fenômeno Religioso. } \\
\text { - } \quad \text { Ecumenismo e Diálogo Inter-Religioso. } \\
\text { - } \quad \text { (Re)construindo formas de manifestação do Transcendente. } \\
\text { - }\end{array}$ \\
\hline
\end{tabular}

Fonte: AMAPÁ (2016).

A estrutura curricular proposta na Tabela 2, evidencia a adoção de posturas que promovam a construção de nova identidade para o ensino público estadual conferindo o estatuto de Ciência assentada em objetivos, conteúdos, metodologia e avaliação, através de uma concepção pluralista e humanista, em que se garanta espaço de desenvolvimento e habilidades cognitivas e relacionais, com respeito à cultura e a diversidade religiosa dos povos que partilham significados e sentidos de experiências e práticas de valores essenciais à convivência humana (AMAPÁ, 2016).

Dessa forma, os conteúdos que foram estruturados na Tabela 2, estão em conformidade com o preconizado nos marcos normativos e competências gerais da Base Nacional Comum Curricular (BNCC) para o ER, salientando entre seus principais objetivos, os seguintes:

a) Proporcionar a aprendizagem dos conhecimentos religiosos, culturais e estéticos, a partir das manifestações religiosas 
Religare, ISSN: 19826605, v.16, n.2, dezembro de 2019, p.576-592.

percebidas na realidade dos educandos, considerando as influencia e contribuições históricas da religiosidade indígena e afrobrasileira;

b) Propiciar conhecimentos sobre o direito à liberdade de consciência e de crença, no constante propósito de promoção dos direitos humanos;

c) Desenvolver competências e habilidades que contribuam para o diálogo entre perspectivas religiosas, exercitando o respeito à liberdade de concepções e o pluralismo de ideias, de acordo com a Constituição Federal;

d) Contribuir para que os educandos construam seus sentidos pessoais de vida a partir de valores, princípios éticos e da cidadania (BRASIL, 2018, p. 225-226).

Por tais finalidades descritas no BNCC, o ER planejado para as escolas públicas do Amapá tem estrita relação com o fenômeno religioso no sentido de explica-lo sob o enfoque orientado em diretrizes e leis educacionais que, no caso do Brasil, postulam sobre o modus operandi de os professores desenvolverem suas metodologias, didáticas e planejamentos para repassar o conhecimento do transcendente sob a perspectiva da laicidade, e não influenciado somente por um ou outro posicionamento religioso que possam tirar o real sentido do termo.

Dessa maneira, as práticas pedagógicas estabelecem diferentes maneiras de se transmitir o conhecimento e a experiência religiosa no Ensino Fundamental, por terem seus currículos organizados por uma base nacional comum e uma parte diversificada. Enquanto a primeira visa estabelecer elementos com uma visão global do estudante, a segunda valoriza as características regionais e locais da sociedade, a cultura e a economia.

O ER é uma tarefa desafiadora, que não pode se influenciar por apenas uma concepção religiosa, mas deve adotar em suas práticas educativas a laicidade e as reformulações promovidas pelas legislações educacionais em nível nacional, as quais, em sua totalidade garantem uma educação para todos, igualitária e provedora de acesso ao processo ensino e aprendizagem, sem utilizar métodos ou conteúdos seletivos e nem modelos para se afirmar o trabalho do fenômeno religioso na escola. 
Religare, ISSN: 19826605, v.16, n.2, dezembro de 2019, p.576-592.

\section{Expectativas de aprendizagens para o ER no Ensino Fundamental das escolas públicas do Amapá}

A BNCC para o ER, salienta competências específicas que precisam ser orquestradas pelos(as) professores(as) de ER para o Ensino Fundamental (EF), sendo propostas como essenciais, pois em primeira instancia, devem promover nos alunos(as) o conhecimentos sobre os principais aspectos divergentes e similares entre tradições/movimentos religiosos e filosofias de vida.

Por-isso, depreende-se que há escolas públicas que no Amapá, os(as) professores(as) trabalham o componente ER de modo contrário ao que preconizam as leis, mostrando a tendência daqueles que lecionam sem serem habilitados ou terem qualificação para o fazê-lo que ensinam sem uso de estratégias pedagógicas por não terem esse conhecimento e formação na área, e aqueles que possuem cursos de formação inicial e continuada na área de ER que precisam romper paradigmas e garantir um ensino aprendizagem imparcial (VULCÃO, 2016).

Por isso, há dificuldades em se avaliar o ER, mostrando que a causa das práticas discriminatórias, preconceituosas, que excluem os diferentes e as minorias, decorrem, principalmente, da incapacidade profissional do(a) professor(a) lecionar e não saber ministrar rompendo-se das práticas discriminatórias e adotando uma postura de inclusão de todos os alunos nas estratégias de ensino.

Outra expectativa de aprendizagem para os alunos(as) do ER que também foi elencada pelo BNCC, há a necessidades dos(as) professores(as) em suas práticas pedagógicas condensarem seus esforços para a diversidade das manifestações religiosas e filosofias de vida, de modo que a aprendizagem se volte para a caracterização e pesquisa das experiências e saberes descritos no percurso histórico, e que possam, concomitantemente, reproduzir e produzir conhecimentos sobre diferentes tempos, espaços e territórios (MONTEIRO, 2012). 
Religare, ISSN: 19826605, v.16, n.2, dezembro de 2019, p.576-592.

Ao proibir o proselitismo religioso, as legislações nacionais e normas estaduais, assegura que o ER não deverá mais ser confundido com educação religiosa, pois a confessionalidade ameaça a justiça religiosa, não promove a diversidade e, além disso, não garante a igualdade ente os grupos religiosos. Assim, faz-se necessário respeitar a diversidade cultural e religiosa brasileira, contemplando todos os segmentos religiosos historicamente rejeitados no processo de escolarização da disciplina (CUSTÓDIO, 2016).

Os(as) professores(as) de ER devem planejar e estabelecer meios de aprendizagem que favoreçam os(as) alunos(as) se reconhecerem como cidadãos que participam dos fenômenos religiosos de sua coletividade, e assim, devem garantir o entendimento e valor para si, para o outro, para a coletividade e para a natureza, e dessa forma, relacionar constantemente a religião como expressão de valor da vida.

Elivaldo Custódio (2015) em seus estudos, identificou que embora a Resolução no 14/2006-CEE/AP estabeleça que deva ser contemplado até o 9o ano, na prática esse sistema funciona em conformidade com a legislação nacional (LDB), que dirmiu sobre a possibilidade de as escolas atuarem de forma autônoma para organizarem e estabelecerem seus currículos, desde que cumprissem um mínimo de disciplinas, por isso, há uma fiscalização e/ou acompanhamento quanto à condição de oferta e ministração do ER nas escolas públicas. Os(as) professores(as) ministram suas aulas utilizando metodologia própria. Da mesma forma, algumas escolas se organizam ofertando esta disciplina somente até ao $8^{\circ}$ ano, enquanto outras ofertam somente até ao $7^{0}$ ano. No caso do ensino modular que é o trabalho realizado no interior do Estado, não há oferta do ER, bem como professor designado ou especializado para esta modalidade de ensino. E chama o autor, a atenção para a questão da participação das religiões de matrizes africanas nesse contexto:

Percebemos que a COODNOPE, o NATEP, o NEER e a UOCUS criadas, com a finalidade de nortear a Educação do Estado do Amapá no que tange à diversidade religiosa, trata-se de mais um 
Religare, ISSN: 19826605, v.16, n.2, dezembro de 2019, p.576-592.

grupo de trabalho que não está livre do jogo do poder, por não contemplar o reconhecimento da identidade cultural religiosa brasileira, ou mesmo apresentar qualquer proposta significativa de trabalho para "ouvir" as diversas organizações religiosas. Entendemos com isso, que sem a valorização e o respeito às RMA na disciplina de ER e no Ensino da Cultura e História da África e dos Afro-brasileiros não prevalecerá o dispositivo legal na preservação e valorização da cultura (CUSTÓDIO, 2015, p. 37448).

Há indícios de que a diversidade religiosa não tem sido considerada dentro das ações dos órgãos oficiais do governo e que há grandes dificuldades em se concretizar o diálogo inter-religioso. E, segundo Elivaldo Custódio (2015), enquanto não houver interação entre as esferas governamentais e não governamentais nos processos de elaboração, execução e implementação de Politicas Educacionais reais com práticas concretas, não haverá mudanças estruturais significativas na educação pública, nem tão pouco, melhoras na qualidade do ensino e o atendimento às exigências de uma educação étnico racial.

Defende-se também, com base no BNCC que os professores(as) de ER de EF das escolas públicas de Macapá possam desenvolver estratégias pedagógicas e metodológicas que contribuam para a convivência com a diversidade de crenças, pensamentos, convicções, modos de ser e viver.

As práticas pedagógicas dos(as) professores(as) de ER do EF no Amapá, podem utilizar nas suas aulas recursos pedagógicos para que os(as) alunos(as) consigam empreender e relacionar a presença das tradições religiosas em vários campos de presença de seres humanos e de religiões (como por exemplo: aspectos culturais, políticos, econômicos, da saúde, da ciência, da tecnologia e do meio ambiente); e também, voltar-se para a adoção de consciências críticas e reflexivas, através de debates dos problemas que envolvam as questões de intolerância, discriminação e violência de cunho religioso, de modo a assegurar os direitos humanos no constante exercício da cidadania e da cultura de paz.

Estratégias que podem ser postas em práticas nas escolares públicas do Amapá a partir de encontros, nos quais, as estratégias pedagógicas dos(as) 
Religare, ISSN: 19826605, v.16, n.2, dezembro de 2019, p.576-592.

professores(as) possam promover o diálogo, o conhecimento e o respeito diante da variedade cultural religiosa e não religiosa, sem uso de práticas proselitistas e intolerantes. Diante deste pensamento os(as) professores(as) tem um papel de suma importância que corresponde à constituição de uma educação humanizadora, com saberes e aprendizagens significativas, em prol da igualdade de direitos e do bem viver entre as inúmeras variedades culturais que integram e embelezam o planeta que pertence à raça humana, independente das diferenças.

\section{Conclusão}

Há métodos pedagógicos que se tornaram utilizados pelos(as) professores(as) de ER no EF por visualizarem a mudança do contexto histórico e social dos(as) alunos(as). Dessa forma, cita-se Paulo Freire, que buscou por meio da formação tornar os(as) professores(as) capazes de gerar mudanças nos processos de ensino, capacitando-os, em consequência, a tornarem os(as) alunos(as) sujeitos da mudança de sua história individual e coletiva, o mesmo defendia o diálogo como veículo pedagógico capaz de libertar das concepções que intervêm no mundo. No caso do ER, os princípios da Educação Popular apontam para uma relação sujeito-sociedade e cultura a partir de uma nova prática pedagógica, uma educação libertadora.

O ER na educação básica é uma tarefa desafiadora, que não pode se influenciar por apenas uma concepção religiosa, mas deve adotar em suas práticas educativas a laicidade e as reformulações promovidas pelas legislações educacionais em nível nacional e estadual, as quais, em sua totalidade garantem uma educação para todos, igualitária e provedora de acesso ao processo ensino e aprendizagem, sem utilizar métodos ou conteúdos seletivos e nem modelos para se afirmar o trabalho do fenômeno religioso na escola.

\section{Referências}


Religare, ISSN: 19826605, v.16, n.2, dezembro de 2019, p.576-592.

AMAPÁ, Conselho Estadual de Educação do. Resolução n.ํ 14 de 15 de março de 2006. Dispõe sobre a oferta do ensino religioso no nível fundamental do sistema educacional do estado do Amapá. Disponível em: <https://ipfer.com.br/gper/wpcontent/uploads/sites/2/2017/12/AMAP\%C3\%81-Resolu\%C3\%A7\%C3\%A3o.pdf >. Acessado em: 10 abr. 2019.

AMAPÁ, Governo do Estado do. Diretrizes Curriculares da Educação Básica do Estado - 2016. Proposta Curricular - Ciências Humanas: Ensino Religioso. Amapá: Secretaria de Estado da Educação, 2016.

AMAPÁ, Governo do Estado do. Referencial Curricular Amapaense: Educação Infantil e Ensino Fundamental. Amapá: SEED, 2017.

BRANCO, Gustavo Leite Castello. Uma análise multidimensional da prática do proselitismo no ensino religioso frente ao art. 33 da LDB. Summae Sapientiae, v. 1, n. 1, p. 186-203, 2018.

BRASIL. Base Nacional Comum Curricular. Brasília: EDUCERE, 2018. Disponível em:

$<$ http://www.unicap.br/observatorio2/wpcontent/uploads/2018/05/Compila\%C3\%A7\%C3\%A3o-ER-BNCC.pdf>. Acessado em: 10 abr. 2019.

BRASIL. Lei n. 9.394 de 20 de dezembro de 1996. Estabelece as diretrizes e bases da educação nacional. Disponível em: <http://www.planalto.gov.br/ccivil_03/LEIS/L9394.htm>. Acessado em: 10 abr. 2019.

BRASIL. Parecer CES/CNE n. 09 de 8 de maio de 2001. Diretrizes Curriculares Nacionais para a Formação de Professores da Educação Básica, em nível superior, curso de licenciatura, de graduação plena. Disponível em: <http://portal.mec.gov.br/cne/arquivos/pdf/009.pdf>. Acessado em: 10 abr. 2019. CAVALCANTE, M. das G. M. Multiculturalismo e ensino religioso: considerações iniciais. 2019. 28f. Trabalho de Conclusão de Curso (Graduação em História)Universidade Estadual da Paraíba, Guarabira, 2019.

CURY, Carlos Roberto Jamil. Ensino religioso na escola pública: o retorno de uma polêmica recorrente. Revista Brasileira de Educação, v. 1, n. 27, p. 183-213, 2018.

CUSTÓDIO, Elivaldo Serrão. Currículo e inclusão escolar: um olhar sobre o ensino religioso e as religiões de matrizes africanas na educação pública estadual no Amapá. Anais XII Congresso Nacional de Educação, Paraná, 22 a 26 de outubro de 2015. CUSTÓDIO, Elivaldo Serrão. Ensino religioso e relações étnico-raciais no Amapá: Saberes, Valores e Práticas. Anais do Congresso Internacional da Faculdades EST. São Leopoldo: EST, v. 3, n. 1, p. 95-102, 2016.

DORVILLÉ, Luís Fernando Marques; SELLES, Sandra Escovedo. Ensino de evolução e criacionismo na educação básica: ressignificação de um debate em tempos sombrios. In: D'AVILA-LEVY, Claudia Masini; CUNHA, Luiz Antônio (Orgs.). Embates em torno do Estado laico. São Paulo: SBPC, 2018. p. 131-162.

FIGUEIRÊDO, Adriana Guilherme Dias da Silva. O ensino religioso no espaço público escolar: uma análise da tradição cristã na abordagem pós-colonial. 2017. Dissertação (Mestrado) - Universidade Católica de Pernambuco. Pró-Reitoria Acadêmica. Coordenação Geral de Pós-Graduação. Mestrado em Ciências da Religião, 2017. 
Religare, ISSN: 19826605, v.16, n.2, dezembro de 2019, p.576-592.

MONTEIRO, Tatiane Galvão. O uso das mídias no ensino religioso numa perspectiva marxista: Uma proposta para o ensino fundamental de $5^{o}$ e $6^{\underline{o}}$ anos. 2012. $57 \mathrm{f}$. Monografia (Especialização em Mídias na Educação). Universidade Federal do Amapá, Macapá, 2012.

OLIVEIRA, Aurenéa Maria de; MIRANDA, Marcelo Henrique Gonçalves de; SILVA, Maria Amanda Micaely Pinheiro da. Questões de gênero, sexualidade e laicidade no ensino público tendo como eixo de debate a disciplina de ensino religioso em escolas de Recife. ETD - Educação Temática Digital, v. 20, n. 4, p. 864886, 2018.

PINTO, Sofia Alexandra Ribeiro Rocha da Silva. Laicidade e Religião Civil. 2017. 60 f. Dissertação (Mestrado em Ciências Jurídico-Políticas). Faculdade de Direito, Universidade do Porto, Portugal, 2017.

REIS, Marcos Vinicius de Freitas; ANJOS, Katia Ma Barbosa dos. Ensino Religioso no Amapá: um olhar sob uma escola pública estadual. Áskesis, v. 6, n. 1, p. 19-29, 2017.

ROCHA, Magna Celi Mendes da. O ensino confessional e a dimensão religiosa da educação: liberdade e formação humana. Scientia Canonica, v. 1, n. 1, 2018.

SILVA Jair Gomes da; COELHO Lázara Divina. Os fundamentos filosóficos da escola cristã no contexto brasileiro. Vox Faifae: Revista de Teologia da Faculdade FASSEB, v. 8, n. 1, p. 1-39, 2018.

VULCÃO, Maria De Lourdes Sanches. Ensino Religioso no Amapá: uma disciplina em construção (2006-2011). 2016. 141 f. Dissertação (Mestrado em Educação). Universidade Federal de Goiás, Catalão, 2016.

Recebido em 13-04-2019.

Aprovado em 08-08-2019. 